\title{
What is in the name? Content analysis of questionnaires on perceived quality of one's work life
}

\author{
Renaud Gaucher $^{1}$ (D) $\cdot$ Ruut Veenhoven ${ }^{1,2}$ (D)
}

Accepted: 11 May 2021 / Published online: 12 June 2021

(c) The Author(s) 2021, corrected publication 2021

\begin{abstract}
There is a great demand for information on how workers evaluate the quality of their jobs. In response to this demand, a multitude of questionnaires has been developed, which are presented under different names and stress different aspects of work life. It is therefore difficult to see what questionnaire is best suited to one's information demand. This problem can be solved by considering the content of the different questionnaires through the same conceptual lens, focussing on the meaning of each of the constituting questions separately. In this paper, we adapted Veenhoven's conceptualization of qualities of life in general to the work setting, which gave us a matrix of 9 nested notions of perceived quality of a worker's work life, and then used this matrix to classify the meaning addressed in 12 questionnaires. Some of these questionnaires appear to address a clear meaning, while others cover a mix of meanings. These contents are presented in a tabular overview here to allow users to select the questionnaire the most adapted to their needs. This approach can also be used to develop new questionnaires on perceived quality of work life.
\end{abstract}

Keywords Content analysis · Self-report · Wellbeing at work · Quality of work life · Job satisfaction $\cdot$ Happiness at work

\section{Introduction}

\subsection{Practice of measurement of perceived quality of work life}

A lot of work has been done on how workers evaluate the quality of their job. An advanced search in Google Scholar on October 20, 2020, yielded the following hits on related terms: 'satisfaction with work': 26,000 hits 'job satisfaction' 1,710,000, 'quality of work'

Renaud Gaucher

renaudgaucher@gmail.com

Ruut Veenhoven

veenhoven@ese.eur.nl

1 Erasmus Happiness Research Organization, Erasmus University Rotterdam, Burg. Oudlaan 50, Van der Goot Building, M5-43, 3062 PA Rotterdam, The Netherlands

2 Optentia Research Program, North-West University, Vanderbijlpark, South Africa 
300,000, 'happiness at work' 6210, 'work happiness' 3540, 'employee happiness' 3130, 'employee wellbeing 10,900 and 'well-being at work' 6240.

In addition to this academic research, there is commercial trade in the measurement of perceived quality of work designed to serve the information demands of organizations. One of the reasons for this demand is that an understanding of workers' subjective perceptions of the quality of their work provide management with indications of the objective quality of the workers' work conditions and the need to invest in improving these conditions. Another reason for this demand is that managers expect that satisfied workers will be more productive and less inclined to report sick or quit. Therefore, managers want to know whether investments in worker satisfaction are required and which aspects of the work situation they should focus on. A related reason is that dissatisfied workers tend to demand compensatory pay rises, both by individual workers and in collective bargaining situations with trade unions. In addition to these material concerns, there is also the moral requirement for managers to have an interest in the worker's wellbeing. Such information is increasingly quantified in the reports of 'social accountability' of organizations.

There is also a more general interest in how workers typically see the quality of their work and in particular how satisfied they are with their job. The average annual hours worked in 2017 was 1759 in OECD countries. This means that the satisfaction experienced in these hours will affect the general satisfaction climate in a country, and this is likely to affect acceptance of the prevailing socio-economic order. Consequently, satisfaction with work is also a standard topic in national social reports, such as the Quality of American Life (Campbell et al. 1976) and the Enquête sur la qualité de vie (INSEE 2011).

The practice of measuring quality of one's work has resulted in a plethora of questionnaires, such as the Quality of Working Life Systemic Inventory (Martel and Dupuis 2006), the Quality of Work Life Measure (Sirgy et al. 2001) the Work-Related Quality of Life scale (Van Laar et al. 2007), the Generic Job Satisfaction Scale (Macdonald and MacIntyre 1997) and the Job Satisfaction Survey (Spector 1985). In addition to these 'general' measures of quality of work life, there are questionnaires tailored to specific occupations, such as for teachers the Questionnaire of Teachers' Work Life Quality (Javadi et al. 2019) and the Teacher Job Satisfaction Questionnaire (Lester 1987), and for nurses the Brooks and Anderson's (2005) quality of nursing work life questionnaire and the Nursing Home Nurse Aide Job Satisfaction Questionnaire (Castle 2007).

This variety in the types of questionnaires available for the measurement of self-perceived quality of one's work life also exists for other domains of life, such as one's health, which is often measured using multi-item questionaires on 'Health-Related-Quality Of Life' abbreviated HRQOL and also referred to as Patient Reported Outcomes (PRO). A 'general' measure of this kind is the 100-item Rand Health Insurance Study Questionnaire (Brook et al.1979), best known in its shortened 36 item version SF36 (Ware and Sherbourne 1992), a disease-specific questionnaire on one health condition for cancer patients is the EORTC Quality of Life Questionnaire (EORTC 2020).

\subsection{Uncertainty about meanings measured}

It is not always clear what questionnaires actually measure. Common names of questionnaires such as the Minnesota Satisfaction Questionnaire (MSQ; Weiss et al. 1967) and the Job Descriptive Index (JDI; Smith, Kendall \& Hulin, 1969) are not very informative. There is typically more information contained in the names given to subscales in a questionnaire, such as the sub-scale 'flow and intrinsic motivation' in Singh and Aggarwal's (2018) 
Happiness at Work Scale, however, the notions referred to in such names are often not well defined.

In theory, scale development starts from a clear concept and researchers select items that validly tap into this concept. In this vein MacKenzie et al. (2011) divide the development of a questionnaire into 10 steps: (1) development of a conceptual definition of the construct, (2) generation of items to represent the construct, (3) assessment of the content validity of the items, (4) formal specification of the measurement model, (5) data collection to conduct pretest, (6) scale purification and refinement, (7) data gathering from new samples and re-examination of scale properties, (8) assessment of the scale validity, (9) cross-validation of the scale, and (10) development of norms for the scale. In practice, however, there is often not a clearly defined concept at start, but rather a fuzzy notion as the following review of definitions illustrates.

\section{Notions of worker wellbeing}

The quality of work life (QWL) has been defined in different ways and typically not very sharply. Carlson (1983) considers that QWL is a goal, an ongoing process for achieving that goal, and a concept of management. The goal of QWL is to create more involving, satisfying, and effective jobs and work environments for people at all levels of an organization. The basic idea of QWL as a concept of management is that a climate has to be fostered in which the fundamental human dignity of all members of the organization is recognized. Nadler and Lawler (1983) consider that QWL is a way of thinking about people, work, and organizations; QWL consists of two distinct elements: concern for the impact of work on people and organizational effectiveness, and the idea of fostering participation in organizational problem solving and decision-making. Kiernan and Knutson (1990) see QWL as a philosophical commitment to the development of an interactive relationship between employee and employer. Their main question is: 'What must we do to meet the needs and expectations of all involved, such that people in organizations will have healthy work relationships?' For a review of the definitions of QWL, see Bagtasos (2011) who notes that the quality of work life in organizations is usually measured using the level of satisfaction of employees. This practice involves a conceptual shift to the worker's perspective.

Job satisfaction would seem to be a more discrete concept, but definitions also differ in this case and lack clear boundaries. Hoppock (1935) introduced the concept of job satisfaction and defined it as a combination of psychological, physiological and environmental circumstances that cause a worker truthfully to say that he or she is satisfied with his or her job. Locke (1969) defines job satisfaction as the pleasurable emotional state resulting from the appraisal of one's job as achieving or facilitating the achievement of one's job values. Spector (1997) is the clearest in his definition: job satisfaction is 'the degree to which people like their jobs'. For a review of the definitions of job satisfaction, see Aziri (2011).

Rather than departing from a sharp a-priory definition, some researchers start from a 'sensitizing' notion and distil meaning later from the clusters they see in the intercorrelations of items they deemed indicative for this ambiguous matter. It means that they let psychometrics decide what they should have decided before using psychometrics. An example is the debate about the structure of the MSQ (Fields, 2002), where meanings are changed from a researcher to another and are elaborated after the development of the questionnaire. This kind of debates arises from differences in samples, techniques of correlational analysis researchers used and their interpretations of observed clusters. 


\subsection{Limitations to correlational identification of meaning}

Questionnaire development depends heavily on correlational analysis, assuming that correlations in response to questions mean that these questions measure the same thing. Although this will often be the case, it is not always true; e.g. body weight and body length are correlated, they are not the same. Correlations can also be spurious, driven by a common third factor. This is particularly problematic in the measurement of illdefined syndromes of interrelated causes and effects as is the case here. This fundamental problem cannot be solved using mathematically sophisticated methods.

Correlational analysis also is of limited use in assessing validity. If we lack a clear concept of what we are testing, we cannot directly assess whether the questionnaire adequately measures the concept it is supposed to measure. Hence validity testing is limited to indirect indications, such as whether the questionnaire measures the same thing (substantive validity), differs from other phenomena (discriminant validity), and correlates with related matters in the future (predictive validity). Such an analysis only tells us whether a questionnaire taps a distinct phenomenon, but not what this phenomenon is.

\subsection{Identifying meanings in the text of questions}

The first steps in scale development after deciding about the definition of the construct are generation of items to represent the construct and assessment of the content validity of these items. These steps are often covered too briefly in the articles, and not well explained in comparison to the correlational analysis. MacKenzie et al. (2011) recommend Hinkin and Tracey's (1999) procedure. In this technique, researchers construct a matrix in which definitions of different aspects of the construct domain are listed at the top of the columns and the items are listed in the rows, then judges are asked to rate the extent to which each item captures each aspect of the construct domain using a fivepoint Likert-type scale ranging from 1 (not at all) to 5 (completely). To our knowledge, the Hinkin and Tracey's procedure is rarely followed.

\subsection{How we charted meanings addressed in questionnaires on quality of one's work life}

In this paper, we inspected questionnaires' content in retrospect by looking at the items through the lens of a well-defined conceptual grid. We did this in the following three steps:

- step 1: define different qualities of work life

- step 2: assess which of these qualities are addressed by the separate items in questionnaires on quality of work life

- step 3: present the results of the above two steps in a schematic overview.

Our approach could be described as a refinement of the non-mathematical part of the procedure suggested by Hinkin and Tracey (1999) to assess the content validity of items or 
a technique to use before using Hinkin and Tracey (1999) technique. In our approach, the rating is not mathematical and the choices that are made have to be clear and explained. Unlike Hinkin and Tracey (1999), we provide a matrix and rules for writing items according to each category of the matrix.

\subsection{Plan of this paper}

We distinguish different qualities of work life in Sect. 2, this is step 1 in our approach. We present how we selected the questionnaires on quality of work life and assessed which of these qualities are addressed by separate items in these questionnaires in Sect. 3, this assessment is step 2. We present the results for each questionnaire in Sect. 4, this is step 3. We discuss the results and the strengths and weakness of our approach in Sect. 5.

\section{Qualities of work life}

The term 'quality of life' is misleading since there is no one quality of life. The term is in fact an umbrella for different qualities of life. Below we distinguish several such qualities in work life to obtain a conceptual grid which we can use to compare the contents of questionnaires on perceived quality of one's work life.

\subsection{Veenhoven's conceptualization of qualities of life}

Several distinctions for qualities of life have been proposed, each with their own merits (Phillips 2006), however, for the task at hand here, we must choose one perspective. In this paper we orient ourselves on Veenhoven's $(2000,2009)$ distinction between four qualities of life and his subsequent distinctions of four kinds of satisfaction and two components of life satisfaction.

\subsubsection{Four qualities of life}

Many different terms are used to describe human quality of life (QOL), such as 'wellbeing', 'happiness' and 'thriving'. Veenhoven identifies four meanings addressed using these terms, distinguishing between:

- opportunities for a good life and the outcomes of life

- external qualities and internal qualities.

A combination of these two dichotomies yields a fourfold matrix which we present in Scheme 1. 


\begin{tabular}{|l|l|l|}
\hline & Outer qualities & Inner qualities \\
\hline Life chances & $\begin{array}{l}\text { Livability of the } \\
\text { environment }\end{array}$ & Life-ability of the person \\
\hline Life results & Utility of life & Satisfaction with life \\
\hline
\end{tabular}

Scheme 1 Veenhoven's (2000) matrix of the four qualities of life

Livability of the environment. The left top quadrant of Scheme 1 denotes the meaning of good living conditions. Often the terms 'quality-of-life' and 'wellbeing' are used in this particular meaning, especially by ecologists and sociologists. Economists sometimes use the term 'welfare' for this meaning. 'Livability' is a better word, because it refers explicitly to a characteristic of the environment and does not carry the connotation of Paradise. Politicians and social reformers typically stress this quality of life.

Life-ability of the person. The right top quadrant of Scheme 1 denotes inner life chances. That is, how well we are equipped to cope with the problems of life. This aspect of the good life is also known by different names. Doctors and psychologists especially use the terms 'quality of life' and 'wellbeing' to denote this specific meaning. There are more names, however. In biology the phenomenon is referred to as 'fitness' and this term aptly coveys the message that abilities must be seen in the context of environmental demands. On other occasions life-ability is denoted by the medical term 'health', in the medium variant of the word. In positive psychology, the term 'eudaimonic' happiness is often used to denote this meaning, particularly in juxtaposition to 'hedonic' happiness. This quality of life is central in the thinking of therapists and educators.

Utility of life. The left bottom quadrant of Scheme 1 represents the notion that a good life must be good for something more than itself. This presumes some higher value, such as ecological preservation or cultural development. In fact, there is a myriad of values on which the utility of life can be judged. There is no current generic for these external results of a life. Gerson (1976) referred to these kinds of results as 'transcendental' conceptions of quality of life. Another appellation is 'meaning of life', which then denotes 'true' significance instead of mere subjective sense of meaning. Veenhoven (2000) refers the simpler 'utility of life', admitting that this label may also give rise to misunderstanding. Moral advisors, such as pastors, emphasize this quality of life.

Satisfaction with life. Finally, the bottom right quadrant of Scheme 1 represents the inner outcomes of life. That is the quality of a life in the eye of the beholder. As we deal with conscious humans, this quality boils down to subjective appreciation of life. This is commonly referred to by terms such as 'subjective wellbeing', 'life satisfaction' and 'happiness' in a limited sense of the word. There is no professional interest group that stresses this meaning.

\subsubsection{Four kinds of satisfaction}

Veenhoven (2009) expands on the concept of satisfaction in a later publication and distinguishes four kinds of satisfaction, thus creating a sub-matrix within his earlier matrix of four qualities of life. Veenhoven distinguishes between: 
- passing and enduring satisfactions

- satisfaction with life aspects and satisfaction with life as a whole.

Combining these distinctions produces the following fourfold matrix, shown in Scheme 2 .

\begin{tabular}{|l|l|l|}
\hline & Passing & Enduring \\
\hline Parts of life & Instant satisfaction & Aspect/domain satisfaction \\
\hline Life as a whole & Top experience & Life satisfaction \\
\hline
\end{tabular}

Scheme 2 Four kinds of satisfaction

Instant satisfaction. The top left quadrant of Scheme 2 denotes passing pleasures, such as the enjoyment of a meal or appreciation of art. Kahneman (1999) calls it 'instant utilities' and pleas for the measurement of these using techniques of multiple moment assessment.

Satisfaction with parts of life. The top right quadrant in Scheme 2 denotes enduring appreciation of parts of life. That can concern aspects of life, such as how exciting one's life is and domains of life, such as one's marriage. Although part-satisfactions depend on a continuous flow of instant satisfactions, they have some continuity of their own, one can remain satisfied with one's marriage in spite of an incidental row.

Top experience. The bottom right quadrant in Scheme 2 represents the combination of passing experience and appraisal of life-as-a-whole. Top experience involves short-lived but quite intense feelings and the perception of being part of a wider whole.

Life satisfaction. The bottom-right quadrant in Scheme 2 denotes the combination of enduring satisfaction and appraisal of one's life-as-a-whole. In Veenhoven's terminology life satisfaction is synonymous with 'happiness'. The above conceptual differentiations were in fact made to end up with a clear delineation of that concept.

\subsubsection{Two components of life satisfaction}

As a last step in his conceptual specification of quality of life, Veenhoven (2009) argues that 'when evaluating the favorableness of our life, we tend to use two more or less distinct sources of information: our affects and our thoughts' and he refers to the sub-evaluations made by individuals on this basis as 'components' of an overall evaluation of a life. The affective component of life satisfaction is how well we feel most of the time and is called 'hedonic level of affect'. The cognitive component is the extent to which we think that life brings us what we want and is called 'contentment. This view is presented schematically in Scheme 3.

In Veenhoven's (2009) theory of happiness, hedonic level of affect reflects the gratification of universal innate needs while cognitive contentment reflects the meeting of culturally variable, learned wants. Recent research has confirmed Veenhoven's expectation that the affective component dominates in the overall evaluation of life (Kainulainen et al. 2018). 
Global assessment

Sub-totals

Information basis
SATISFACTION WITH ONE'S LIFE AS-A-WHOLE

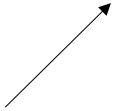

Hedonic level of affect

Balance of pleasant and

unpleasant affects

Affective experience
Contentement

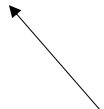

Perceived realization of

wants

Cognitive comparison

Scheme 3 Components of life satisfaction

\subsection{Adaptation of Veenhoven's (2009) conceptual matrices to the work setting}

Veenhoven's taxonomies of quality of life and life satisfaction concern life at large. In this section we apply his conceptual matrices to a particular life domain, that is, work life.

\subsubsection{Four qualities of work life}

If we adapt Veenhoven's matrix of the four qualities of life to the work setting, we obtain the matrix presented in Scheme 4.

\begin{tabular}{|l|l|l|}
\hline & Outer qualities & Inner qualities \\
\hline Life chances & Livability of work conditions & Work-ability of the worker \\
\hline Life results & Utility of work & Satisfaction with work \\
\hline
\end{tabular}

Scheme 4 Four qualities of work life

The matrix differentiates between:

- opportunities for a good work life, i.e. work conditions and work-ability vs outcomes of work, i.e. utility of work and satisfaction with work

- qualities outside the workers, i.e. work conditions and utility of their work, and qualities inside the workers, i.e. their work-ability and satisfaction with work.

Livability of work conditions. The top-left quadrant of Scheme 4 denotes the work situation and includes the demands involved in the work tasks as well as physical and social conditions on the work floor and the social prestige of the job. This aspect of the quality of work life is typically stressed by trade unions and work safety agencies.

Work-ability of the worker. The top-right quadrant in Scheme 4 denotes the worker's capabilities, such as his/her physical and mental health, technical knowledge and 
interpersonal skills. This aspect of the quality of work life is central for HR departments and occupational health services.

Utility of work. The bottom left quadrant in Scheme 4 is about what the work brings to a worker beyond profit to his or her wider environment and concerns the degree to which his or her products serve human needs and her or his social and ecological impact. This aspect of the quality of work is often addressed in motivational speeches and in 'social impact reports' of organizations. It is often difficult to discern rhetoric from reality.

Satisfaction with work. The bottom right quadrant in Scheme 4 refers to the inner outcome of work life on the worker in terms of satisfaction. This is a concern for the workers themselves in the first place and one of the drivers of their behaviour at work. It is for this reason that employers are keen to monitor the satisfaction in their workforce.

\subsubsection{Four kinds of work satisfaction}

If we adapt the matrix of the four satisfactions to the work setting, we obtain the following matrix, presented below in Scheme 5.

\begin{tabular}{|l|l|l|}
\hline & Passing & Enduring \\
\hline Parts of work life & Instant satisfaction at work & $\begin{array}{l}\text { Satisfaction with parts of } \\
\text { work life }\end{array}$ \\
\hline Work life as a whole & Top experience at work & $\begin{array}{l}\text { Overall satisfaction with } \\
\text { work life }\end{array}$ \\
\hline
\end{tabular}

Scheme 5 Four kinds of work satisfaction

Instant satisfaction at work. The left-top quadrant in Scheme 5 denotes passing satisfactions such as contact with colleagues or the feeling of accomplishment once a task is done. Bakker and Oerlemans (2016) refer to this matter as' momentary happiness at work'. Instant satisfactions are not always positive, and also cover such things as irritations and tiredness.

Satisfaction with parts of work life. The top-right quadrant in Scheme 5 represents enduring satisfaction with parts of one's work life. In addition to classical satisfaction with parts of one's work life such as satisfaction with wages and satisfaction with management, there is satisfaction with aspects of work such as satisfaction with the meaningfulness of the work or the degree to which it encourages self-development. 
Top experience at work. The left-bottom quadrant is about top experiences, that is, short-lived 'highs'. States of extasis are not common on a work floor but less intense states of 'flow' are. Flow involves the experience of being immersed in one's work and performing at one's best. Flow occurs more during work than during leisure (Csikszentmihalyi and LeFevre 1989).

Overall satisfaction with work life. The bottom-right quadrant in Scheme 5 denotes the combination of enduring work satisfaction and appraisal of one's work life-as-a-whole. As, in Veenhoven's (2009) terminology life satisfaction is synonymous with 'happiness', we could say that job satisfaction and overall satisfaction with work life are synonymous with happiness at work.

\subsubsection{Components of job satisfaction}

Analogous to the distinction made between components of life satisfaction in Sect. 2.1.3, we can distinguish an affective and a cognitive component in overall satisfaction with work life similar to that presented in Scheme 3. The affective component is called hedonic level of affect at work and the cognitive component contentment at work, see Scheme 6.

Global assessment

Sub-totals

Information basis

\author{
Hedonic level of affect at work \\ Balance of pleasant and \\ unpleasant affects at work
}

Affective experience at work

\section{SATISFACTION WITH ONE'S WORK LIFE}
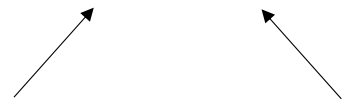

\section{Contentment with work}

Perceived realization of

wants linked to work

Difference between wants

and reality

Scheme 6 Components of job satisfaction 


\subsubsection{The conceptual grid in total}

See Scheme 7.

\begin{tabular}{|c|c|c|c|}
\hline LIVABILITY OF WORK CONDITIONS & \multicolumn{3}{|c|}{ WORK-ABILITY OF THE WORKER } \\
\hline \multirow[t]{4}{*}{ UTILITY OF WORK } & \multicolumn{3}{|c|}{ SATISFACTION WITH WORK } \\
\hline & Instant satisfaction at work & \multicolumn{2}{|c|}{$\begin{array}{l}\text { Satisfaction with parts of } \\
\text { work life }\end{array}$} \\
\hline & Top experience at work & \multicolumn{2}{|c|}{ Overall satisfaction with work } \\
\hline & & $\begin{array}{l}\text { Hedonic level } \\
\text { of affect at } \\
\text { work }\end{array}$ & $\begin{array}{l}\text { Contentment } \\
\text { with work }\end{array}$ \\
\hline
\end{tabular}

Scheme 7 The quality of work life matrix

\section{Method}

Having defined a set of aspects of the qualities of a work life, we can now proceed to see which of these are addressed in current questionnaires on perceived quality of one's work. As a first step we selected some of these questionnaires, then we read each item of each questionnaire carefully to see which aspects of quality of work life were addressed.

\subsection{Selection criteria for questionnaires}

The selection criteria we used to select questionnaires were the following:

- the questionnaire was about perceived quality of one's work life

- the questionnaire was about the current job of the respondents, not their whole career

- the questionnaire was available in English language

- the questionnaire was submitted to minimal psychometric testing, which could include a factorial analysis, the calculation of the Cronbach's alpha, etc.

- the full text of the questionnaire was available as freeware

In order to cover the field, we considered questionnaires presented by their authors under three different names: quality of work life, job satisfaction and happiness at work. Quality of work life and job satisfaction are two names commonly used in questionnaire 
development in organizational psychology, while happiness at work is a new name commonly used in positive psychology. To keep this illustrative exercise manageable, we limited ourselves to 12 questionnaires: 5 under the name of quality of work life, 5 under the name of job satisfaction, and 2 under the name of happiness at work. Very few questionnaires on happiness at work exist. We had no exclusion criteria (Online Appendix).

\subsection{Rating of questions}

We, the two authors of this article, read each item of each questionnaire carefully and located each item in the quality of work life matrix (see Sect. 2.2.4). We did not calculate an interjudge coefficient, as we preferred another option: we had to agree on the reason why we choose a categorization for each item. If we disagreed at first, we had to discuss until we found the most compelling argument, in practice an argument powerful enough to allow us to agree on this argument and then on the location of the item. We have three reasons to justify this option. One, an interjudge coefficient just explains to what extent judges have agreed, it does not tell how to sort the items. Two, judges can sort an item into the same category for different reasons. Three, and this is the main reason, the why is more important than the where, because the quality of a categorization depends on the quality of the reason for this categorization.

\subsection{Some decision rules}

We present below some decision rules we followed to classify the items of the selected questionnaires.

Instant satisfaction at work. To be coded as such, the item should (1) refer to the immediate present, the timeframe is usually given by the lead question, and (2) deal with emotional experience. We have a broad acceptance of what an emotion is although it would be possible to consider basic emotions only (Ekman 1999).

Satisfaction with parts of work life. The items should (1) link to a specific domain, not work as a whole, and (2) refer to satisfaction explicitly. The statement can be made in the item itself, in the lead question or in the response options.

Let us compare the two following items: 'I am satisfied with my work hours' and 'There is a balance between work life and private life'. In the first option, satisfaction is clearly expressed, while one cannot be $100 \%$ sure in the second option as to the extent the respondent is satisfied with his or her work hours. A worker could be satisfied if he or she works less or more; thus, the second item would be rejected. Satisfaction can be an emotional experience rather than a cognitive evaluation. For example, 'I enjoy contact with my colleagues'.

Top experience at work. The items must be about short-lived intense feelings at work, perception of the wholeness or flow at work. Items should be written to target the framework for which they are written directly, and not written to target the framework indirectly, because targeting indirectly can be confusing. An item such as 'I experienced a feeling of flow at work' is written to target the goal of covering flow at work directly, while an item such as 'I am joyful at this specific moment of my workday' does not target the goal of covering flow at work directly. This second item directly expresses the fact of experiencing the positive emotion of joy, not flow at work, thus the second item would be rejected. 
Overall satisfaction with work life. The items should be (1) about work-life as a whole and (2) denote satisfaction.

Hedonic level of affect at work. Items on hedonic level of affect at work differ from items on instant satisfaction at work in that the timeframe can be almost everything but the immediate present. An example of an affect focussed question would be "I feel typically fine at work'.

Contentment with work. Items on contentment with work denote the presence or the lack of a gap between the work life a worker has and the work life he or she wants. An example of an item on contentment with work would be 'My work falls short to my wants'.

Livability of work conditions The item must be (1) about the state of work conditions, and (2) not about satisfaction with it. The second feature is important because items on the livability of work conditions can be easily confused with items on satisfaction with parts of work life.

Work-ability of the worker. The items must be about capabilities such as physical health, mental health, knowledge, and skills. It does not matter whether satisfaction is expressed or not, because the work-abilities of the worker are not domains of satisfaction with parts of work life.

Utility of work. The items must be about (1) utility for society, humankind or moral perfection, and (2) not about satisfaction with this aspect of work. If an item denotes satisfaction with societal utility of work, then the item denotes a satisfaction with parts of work life.

We used a colour code to show to what extent the items of a questionnaire are part of a quadrant of the quality of work life matrix. A quadrant coloured in red indicates that more than half of the items were located in this quadrant. A quadrant coloured yellow indicates that few items, proportionally, i.e. less than $50 \%$, were located in this quadrant. A white quadrant indicates that there are no items located in this quadrant.

Let us imagine that a study of the items in an imaginary questionnaire leads us to draw the matrix shown in Scheme 8. This matrix indicates that our imaginary questionnaire measures the livability of work conditions, satisfaction with parts of work life and hedonic level of affect at work, and that the items about satisfaction with parts of work life represent $50 \%$ or more of the items of the questionnaire.

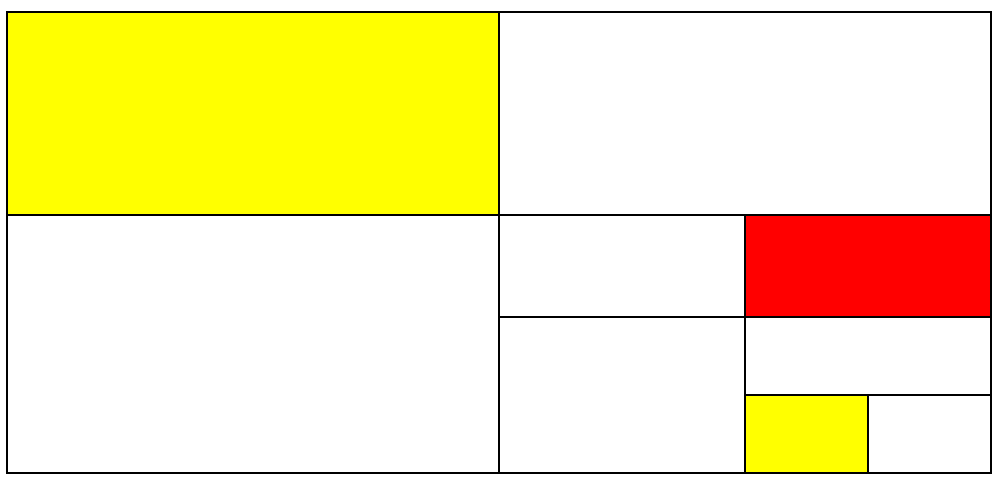

Scheme 8 How QWL matrix is used to locate our imaginary questionnaire 


\subsection{Some illustrative cases of content classification}

Categorizing an item into the QWL matrix can be complicated and debatable, however, if we want to select the right questionnaires or improve the development of questionnaires, we need to categorize items. Below we justify our categorization of 10 items because we want to be transparent about the reasons of our choices and remind readers that our choices are open to debate.

Note: a justification for all 246 items we considered is given in the online appendix.

\subsubsection{Items from questionnaires under the name of 'quality of work life'}

'I feel that I am realizing my potential as an expert in my line of work' (Sirgy et al. 2001).

We categorized this item in the quadrant work-ability of the worker. This item does not tell us anything about the current job of a worker and its influence on the realization of the potential of the worker unlike the item in the same questionnaire 'I feel that my job allows me to realize my full potential'; here a direct causal link is expressed from the work conditions to the realization of the worker's potential. We also categorized the item 'I feel that I'm always learning new things that help do my job better' in the quadrant work-ability of the worker for the same reason.

'A strong trade union is required to protect employees' interests' (Swamy et al. 2015).

We categorized this item as miscellaneous, i.e. outside the matrix. The item expresses a political opinion on the importance of trade unions in employees-employer relationship, and, as relevant this opinion can be, it does not give us any insight into the livability of work conditions inside the organization of a worker who responds to this item.

'I am ready to take additional responsibilities with my job' (Swamy et al. 2015).

We categorized this item in the quadrant work-ability of the worker. The item is not about the perception of the worker on the livability of his or her work conditions, but about his or her perception of his or her ability to take on new responsibilities.

'I feel well at the moment' (Van Laar et al. 2007).

We categorized this item as miscellaneous. There is no mention of the work setting in the item and no leading question that shows that the item falls within the work setting before the item. Thus, the item is about the psychological health of the person in general, not just at work. Items such as 'Recently, I have been feeling unhappy and depressed' and 'I am satisfied with my life' were categorized in a similar manner.

\subsubsection{Items from questionnaires under the name of 'job satisfaction'}

'How do you feel about your job?' with response options ranging from 1 ('delighted') to 7 ('terrible') (Andrews and Withey 1976)

We categorized this item in the quadrant overall satisfaction with work life. The word 'work' can be used in two ways: one to denote the job itself and two, to denote the job 
as a whole, i.e. the work life of a worker. We considered that the second meaning may be more appropriate. Andrews and Whitey use the expression 'the job itself' in another item, however, this item comes after the item we analysed here in their questionnaire.

'How satisfied are you with your present job when you consider the expectations you had when you took the job' (Bacharach et al. 1991)

We categorized this item in the quadrant contentment with work. Contentment with work is about the distance between one's real work life and one's idea of an ideal work life. Here the item deals with the distance between the workers' expectations when hired and the reality of their job. We consider that the breath of meaning of this quadrant could, however, be broadened in light of this item and others such as 'It seems that my friends are more interested in their jobs' (Brayfield and Rothe 1951) and 'How satisfied are you with your present job when you compare it to jobs in other organizations' (Bacharach et al. 1991). The reason for categorizing the item in the quadrant contentment with work is that each of these items contains an idea of distance, comparison between the workers' current job as a whole and jobs or other things.

'All my talents and skills are used' (Macdonald and Maclntyre 1997).

We categorized this item as miscellaneous, because the context of the item was not clearly stated. Talents and skills could be used in leisure time. An example of clear writing for this item would be 'My work allows me to use all my talents and skills'.

'I like doing the things I do at work' (Spector 1985).

We categorized the item in the quadrant satisfaction with parts of work life. The item is about the tasks that a worker does at work and the verb used is 'like', like is used here as a mark of appreciation.

\subsubsection{Items from questionnaires under the name of 'happiness at work'}

'At my work, I remain inspired and try to inspire others as well' (Singh and Aggarwal 2018).

We categorized this item as miscellaneous, because it is a double-barreled item. An item should have just one direction, and this can be divided into two items: 'at my work I remain inspired', and 'at my work, I try to inspire others as well'. We would have classified the item 'at my work I remain inspired' as representative of the hedonic level of affect at work, and the item 'at my work, I try to inspire others as well' as representative of work-ability of the worker.

'My organization provides all necessary training and information to complete work on time' (Singh and Aggarwal 2018).

We categorized this item in the quadrant of the livability of work conditions, because it represents subjective appreciation of a worker's work conditions. There is no degree of satisfaction explicitly stated in the item. An item about satisfaction with parts of work life would be: 'I am satisfied with the training and information my organization provides me to complete work on time'. 


\section{Results}

Using the QWL matrix, close reading and transparent justification of the categorization of items, we analysed each item of 12 questionnaires: 5 under the name of QWL, 5 under the name of job satisfaction, and 2 under the name of happiness at work. Questionnaires on happiness at work are rare for now.

\subsection{Five questionnaires under the name of quality of work life}

\subsubsection{Elizur and Shye (1990)}

Elizur and Shye (1990) developed a 16-item scale on QWL, based on the idea that QWL has two facets: one, mode of functioning, expressive, integrative, adaptive and conservative; and two, fields of functioning, psychological, physical, social and cultural.

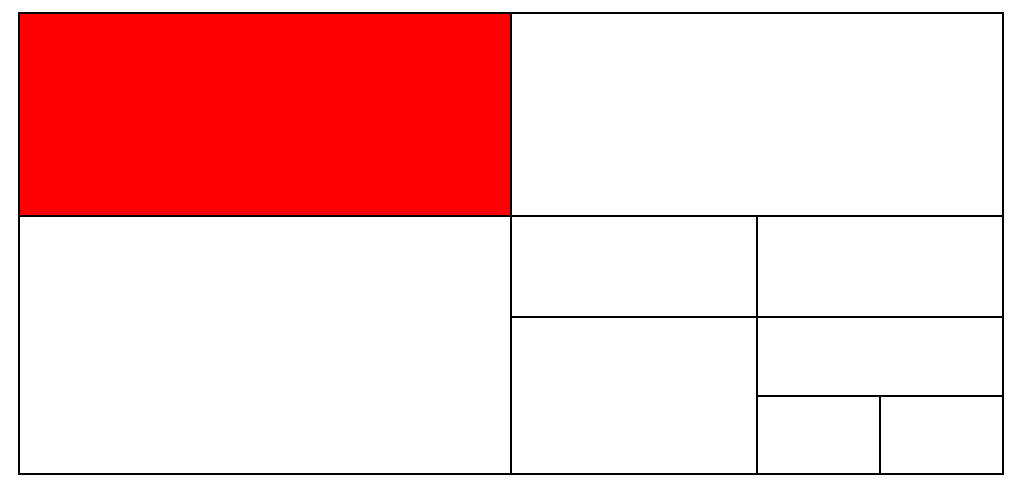

Placed in the QWL matrix the 16 items of Elizur and Shye's questionnaire appear to be all about the livability of work conditions.

\subsubsection{Martel and Dupuis (2006)}

Martel and Dupuis (2006) developed the Quality of Working Life Systemic Inventory (QWLSI), a 33-item scale on the QWL. In this work, each item is about satisfaction with a part of work life. 


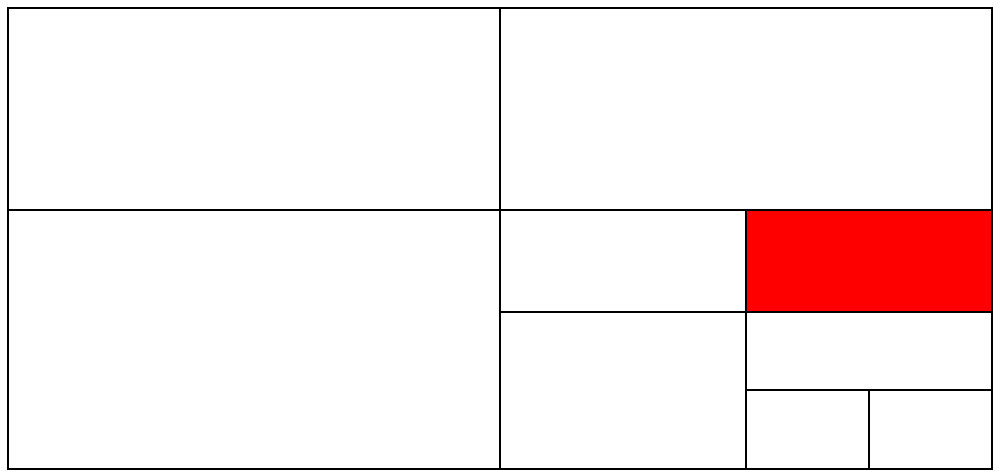

Placed in the QWL matrix all 33 items appear to be about satisfaction with parts of work life. In each item the respondents are asked how 'happy' they are with a specific domain of work life. Aspects of work life are understood in this questionnaire in a broad sense: facilities, i.e. day care, access to restaurants, parking, etc., and union relation are considered to be part of the work life.

\subsubsection{Sirgy et al. (2001)}

Sirgy et al. (2001) developed a 16-item scale, named the Quality of Work Life Measure. The measure was designed to capture the extent to which the work environment, job requirements, supervisory behaviour, and ancillary programs in an organization are perceived to meet the needs of an employee.

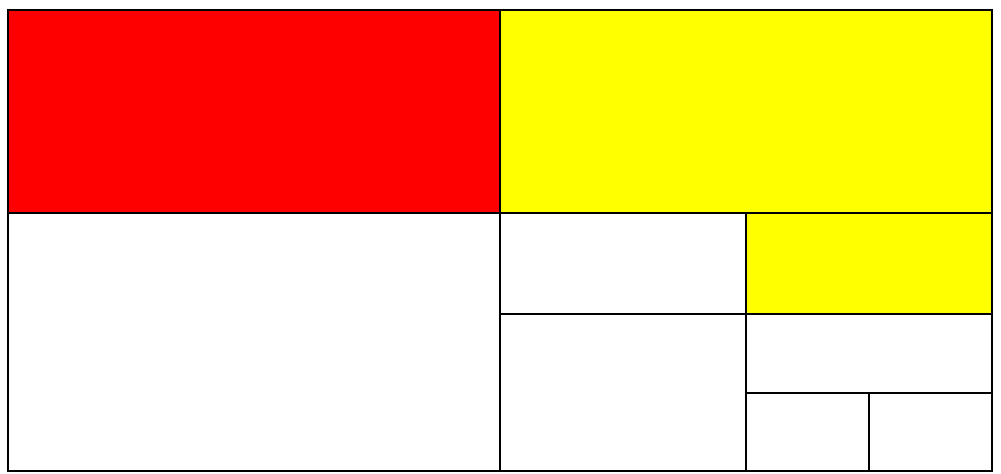

Placed in the QWL matrix 13 items appear to be about the livability of work conditions, 2 items about the work-ability of the worker and 1 item about satisfaction with parts of work life. 


\subsubsection{Swamy et al. (2015)}

Swamy et al. (2015) developed a 49-item scale on QWL with 9 dimensions: work environment, organization culture and climate, relation and co-operation, training and development, compensation and rewards, facilities, job satisfaction and job security, autonomy of work, and adequacy of resources.

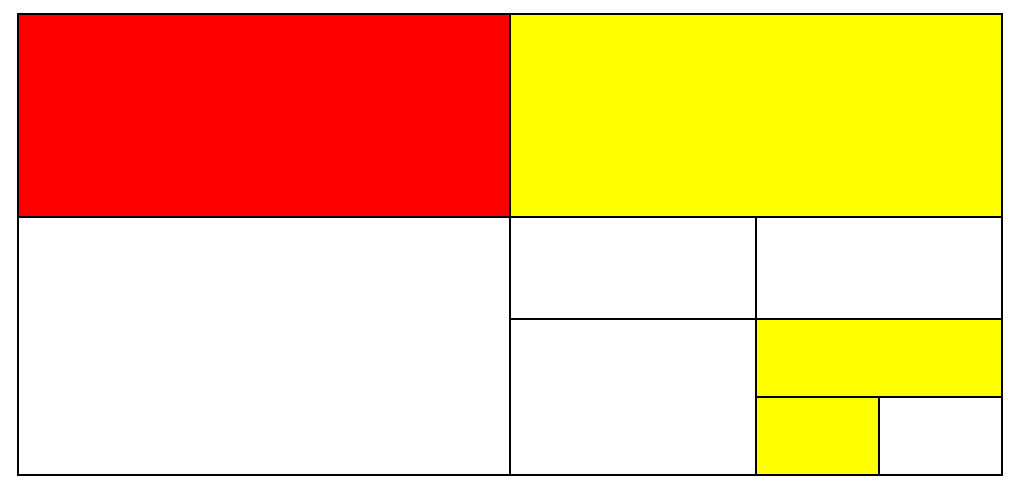

Placed in the QWL matrix 43 items appear to be about the livability of work conditions, 2 items about the hedonic level of affect at work, 1 item about the work-ability of the worker, and 1 about overall satisfaction with work life. Two items had to be categorized as miscellaneous, that is outside the QWL matrix.

\subsubsection{Van Laar et al. (2007)}

Van Laar et al. (2007) developed the Work-Related Quality of Life scale. The scale contains 23 items and 6 dimensions: job and career satisfaction, general well-being, home-work interface, stress at work, and control at work and working conditions.

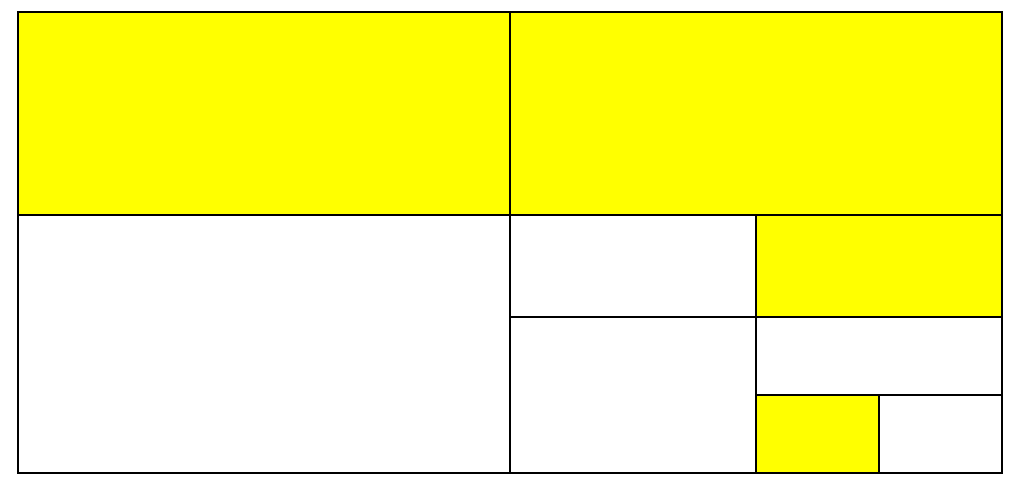

Placed in the QWL matrix the 9 items appear to be about the livability of work conditions, 3 items about the work-ability of the worker, 3 items about satisfaction with parts of 
work life, 2 items about the hedonic level of affect at work and 6 items had to be categorized as miscellaneous, outside the QWL matrix.

\subsection{Five questionnaires under the name of job satisfaction}

\subsubsection{Andrews and Withey (1976)}

Andrews and Withey developed a 5-item questionnaire to measure overall job satisfaction, and Rentsch and Steel (1992) validated the psychometric properties of this questionnaire.

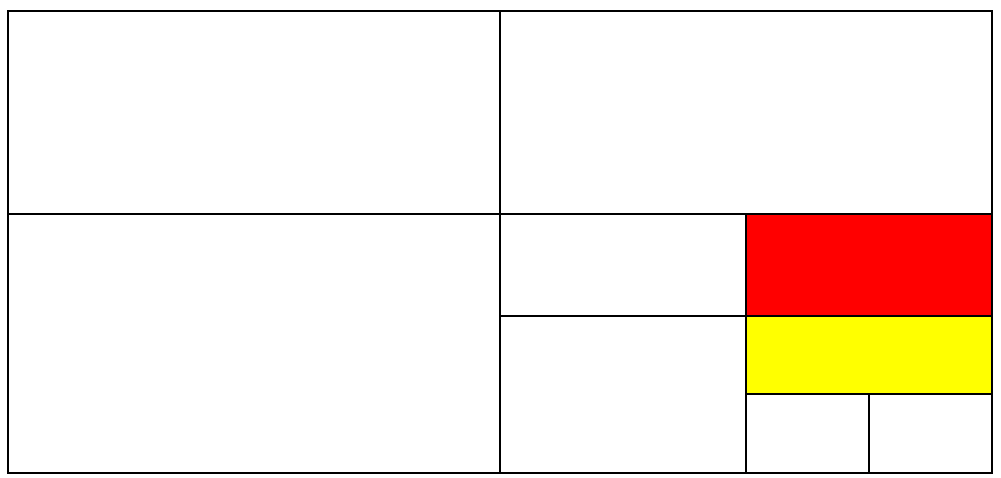

Placed in the QWL matrix 4 items appear to be about satisfaction with parts of work life and one item about overall satisfaction with work life.

\subsubsection{Bacharach, et al. (1991)}

Bacharach et al. (1991) developed a 5-item scale to put an emphasize on the match between expectations and perceived reality for broad aspects of a job taken as a whole.

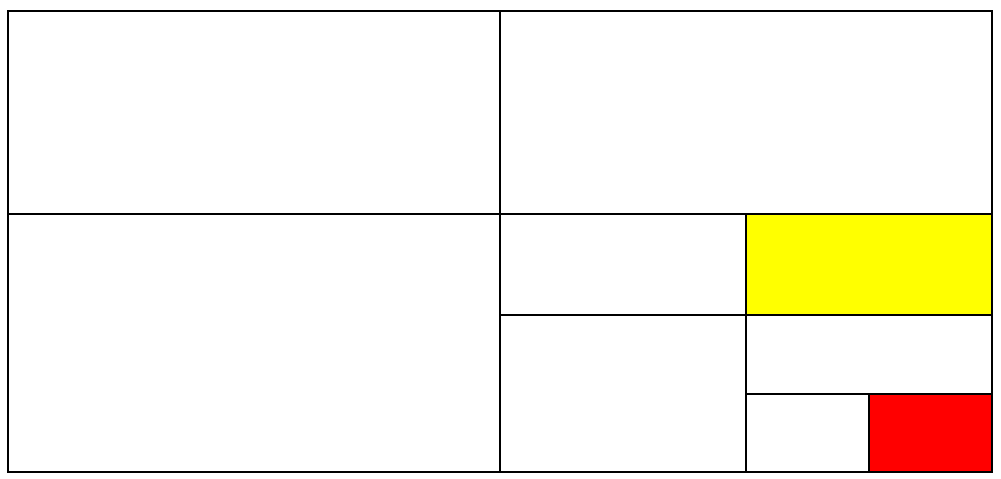

Placed in the QWL matrix 3 items appear to be about contentment with work and 2 items about satisfaction with parts of work life. 
Note: Bacharach et al.'s scale shows a limit of our approach. Contentment with work is about the distance between one's real work life and one's ideal work life. One item in Bacharach et al.'s scale is about the distance between the real job and jobs in other organizations, while another is about the distance between the worker's expectations when hired and the reality of the job.

\subsubsection{Macdonald and Maclntyre (1997)}

Macdonald and Maclntyre (1997) developed the Generic Job Satisfaction Scale, a 10 -item and one-dimension scale on job satisfaction. The items are described as being focused on the employees' feelings or reactions towards aspects of their jobs.

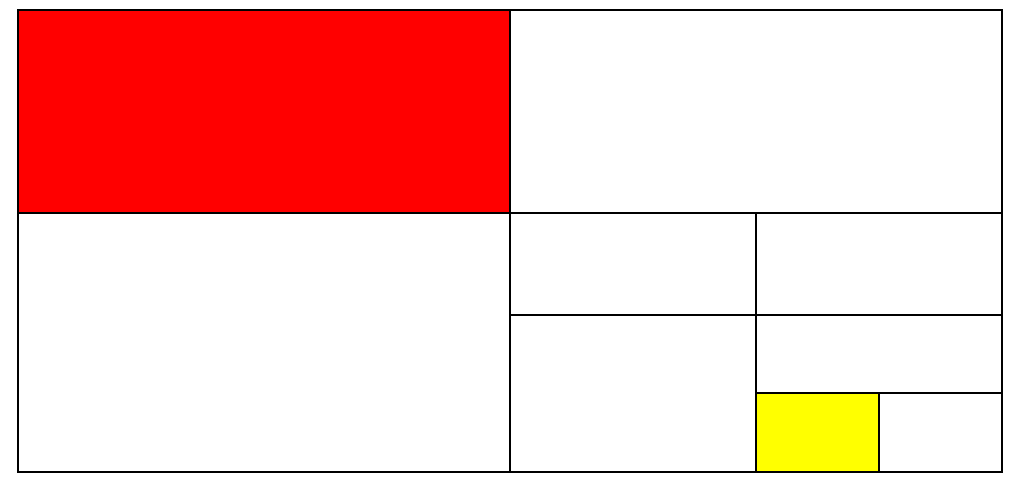

Placed in the QWL matrix 6 items appear to be about the livability of work conditions, 2 items about the hedonic level of affect at work, and 2 had to be categorized as miscellaneous.

\subsubsection{Spector (1985)}

Spector developed the Job Satisfaction Survey (JSS), a 36-item scale and a nine-subscale measure of job satisfaction. He states that this scale is applicable specifically to human service, public, and nonprofit sector organizations. The nine subscales are pay, promotion, supervision, benefits, contingent rewards, operating procedures, co-workers, nature of work and communication. 


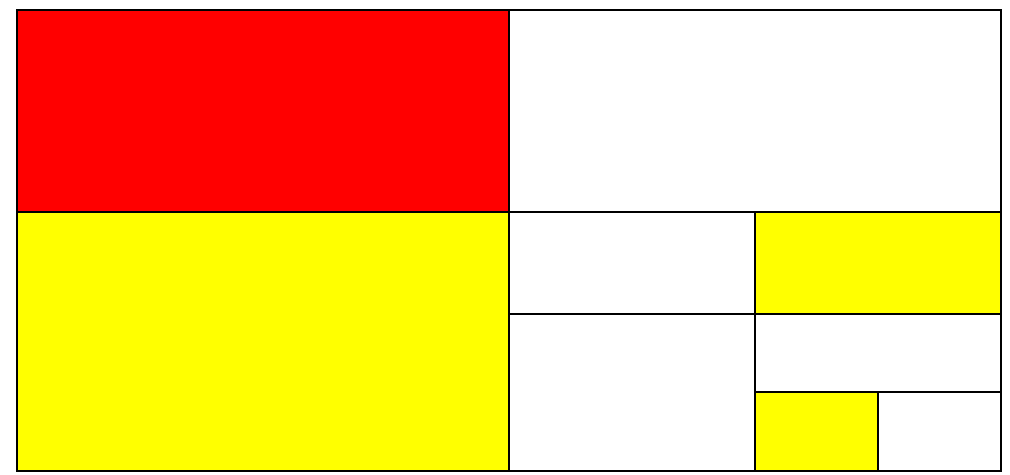

Placed in the QWL matrix 26 items appear to be about livability of work conditions, 7 about satisfaction with parts of work life, 2 about hedonic level of affects at work and 1 about utility of work.

\subsubsection{Weiss et al. (1967)}

Weiss et al. (1967) developed the Minnesota Satisfaction Questionnaire (MSQ). Two forms exist, the long form that consists of 100 items and the short form that consist of 20 items. We studied the short-form questionnaire. The short-form questionnaire consists of three subscales: intrinsic satisfaction, extrinsic satisfaction and general satisfaction.

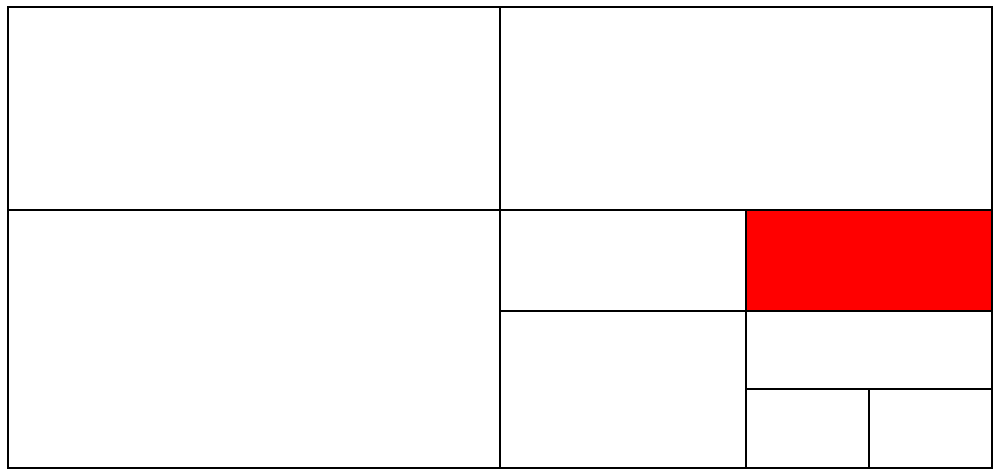

Placed in the QWL matrix all the items appear to be about satisfaction with parts of work life. 


\subsection{Two questionnaires under the name of 'happiness at work'}

\subsubsection{Salas-Vallina et al. (2016)}

Salas-Vallina et al. (2016) consider happiness at work to be an umbrella concept mixing work engagement, job satisfaction and affective organizational commitment, and used three independent scales to measure happiness at work: the Utrecht Work Engagement ${ }^{1}$ Scale (UWES - Schaufeli et al. 2002), the Job Satisfaction Index (JSI-Schriesheim and Tsui 1980), and the Affective Commitment Scale (ACS_Allen and Meyer 1990). The UWES was developed to measure work engagement and is made up of three dimensions: vigour, dedication and absorption. The JSI was developed to measure satisfaction with 5 job conditions and job satisfaction as a whole. The ACS was developed to measure one of the Meyer and Allen's three-component model of organizational commitment, affective commitment. Together the three scales account for 31 items.

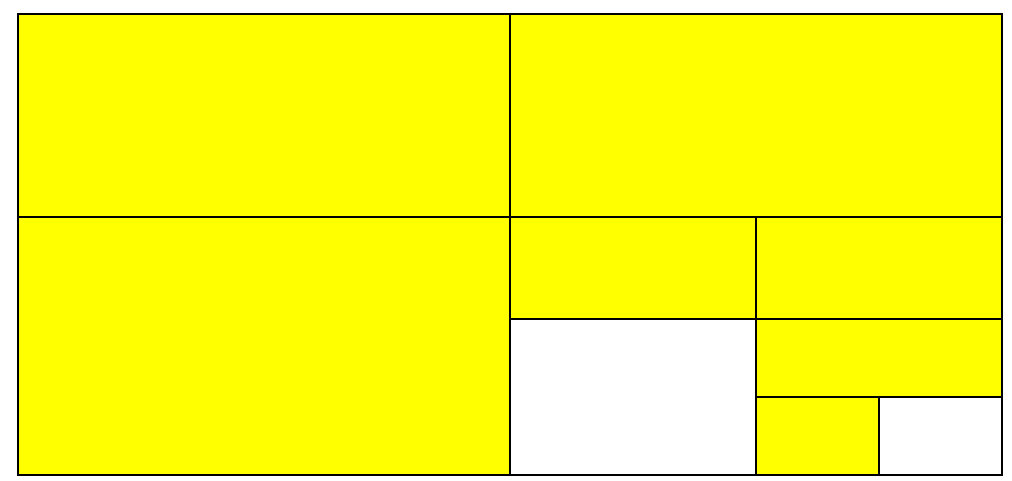

Placed in the QWL matrix 11 items appear to be about satisfaction with parts of work life, 6 items about work-ability of the worker, 5 items about instant satisfaction at work, 2 items about overall satisfaction with work life, 1 item about the livability of work conditions, 1 item about the hedonic level of affect at work and 1 item about utility of work. We also considered that 4 items may not belong to the large and integrative concept of QWL, and we categorized these items as miscellaneous.

\subsubsection{Singh and Aggarwal (2018)}

Singh and Aggarwal (2018) developed the Happiness at Work Scale. The questionnaire has 12 items and 4 dimensions: flow and intrinsic motivation, work repulsive feelings, supportive organizational experiences, and unsupportive organizational experiences.

\footnotetext{
${ }^{1}$ Salas-Vallina et al. (2016) wrote 'Utrecht Work Enthusiasm Scale' rather than Utrecht Work Engagement Scale.
} 


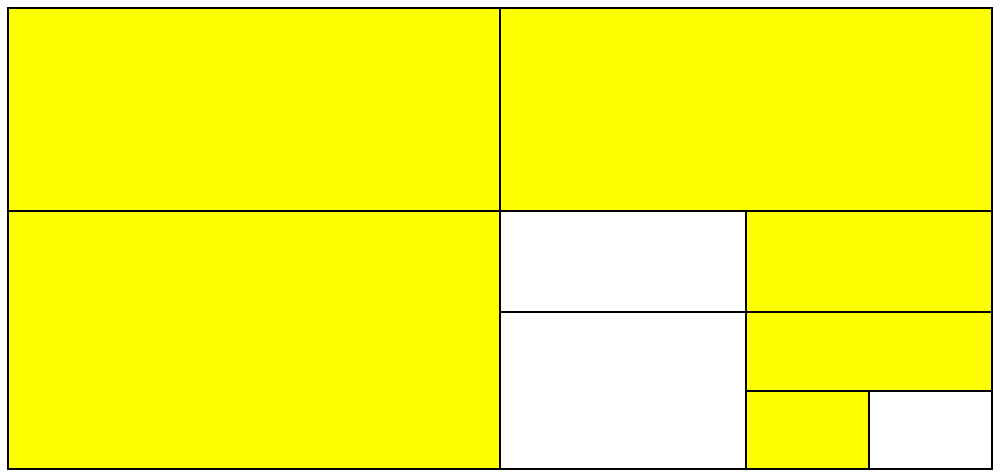

Placed in the QWL matrix 5 items appear to be about the livability of work conditions, 2 about the hedonic level of affect at work, 1 about the work-ability of the worker, 1 about utility of work, 1 about satisfaction with parts of work life work domain and 1 about overall satisfaction with work life. One item was classified as miscellaneous. Almost half of the items measure the livability of work conditions.

\subsection{The overall picture}

We present an overview of the contents of the 12 questionnaires in Table 1, and results are discussed in the next section.

\section{Discussion}

\subsection{Which questionnaire for which topic?}

Some of the analysed questionnaires measure one quality of work life, this is the result of a lead question that gives a context that fits a specific quality or repetition in the writing of each item. The Elizur and Shye questionnaire (1990) measure the perceived livability of one's work conditions. The Martel and Dupuis (2006) and the Weiss et al. (1967) questionnaires measure satisfaction with parts of work life.

Most questionnaires measure more than one quality of work life while measuring a main quality. Sirgy et al. (2001), Swamy et al. (2015), Macdonald and MacIntyre (1997) and Spector (1985) questionnaires mainly measure the livability of work conditions. The Andrews and Whitey questionnaire (1976) mainly measures satisfaction with parts of work life, and the Bacharach et al. (1991) questionnaire mainly measures contentment with work.

Some questionnaires measure more than one quality and do not measure a main quality in particular, in our case the Salas-Vallina et al. (2016) and the Singh and Aggarwal (2018) questionnaires. 


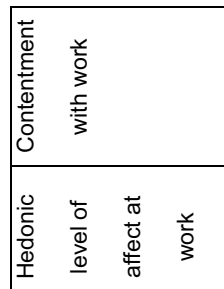

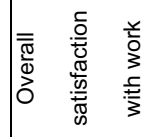

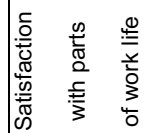

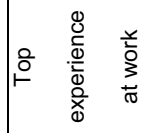

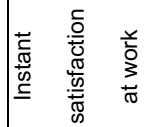

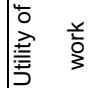
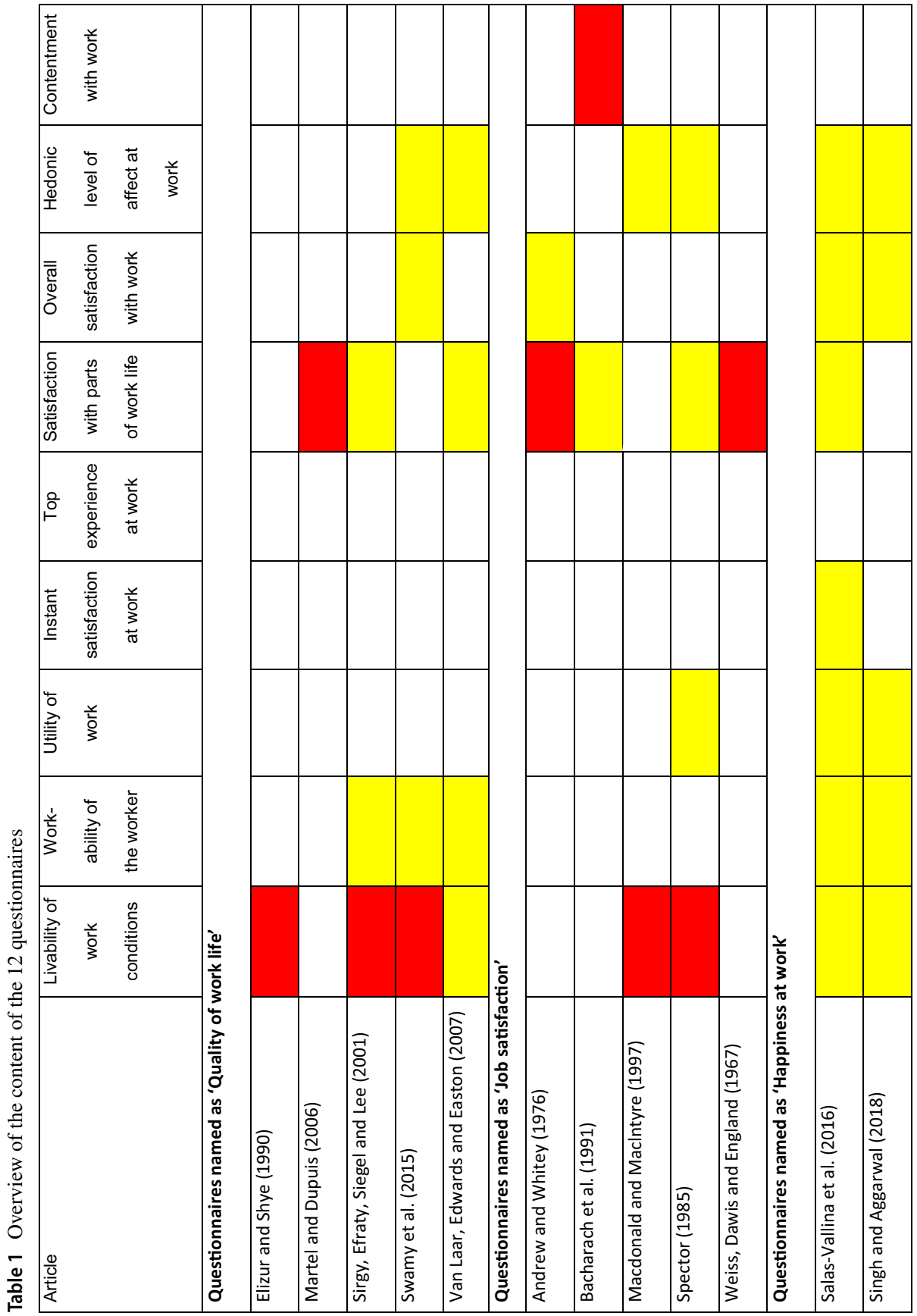

Springer 


\subsection{What do names of questionnaires tell?}

We selected questionnaires presented under three different names. Do these names convey different contents or are they merely brand names? A look at Table 1 shows little systematic difference between most questionnaires and their content, at least when considered through the lens of our conceptual grid. Hence prospective users of questionnaires need to do more than just look at their names.

\subsection{Limitations of the method}

Our method has at least 4 limitations. One, our results depend on the conceptual lens we used, that is, our adaptation of Veenhoven's (2009) distinction of 9 qualities of life to the work setting. An avenue for future research would be to consider other matrices and to compare their application on this same set of questionnaires.

Two, certain items may be difficult to categorize, that is to find a decisive argument to justify the choice made for their categorization. This issue may signal that the item is fuzzy, which is not a limitation of our method, but an advantage, however, this does point to the difficulty of being able to place any item into a specific matrix, in our case the QWL matrix.

Three, any categorization of items depends on the judgements made by the judges doing the categorization. It is possible for judges to find an argument that they think decisive in the moment and not to see a better argument that would help them make another choice about how to categorize an item. This is why transparency and debate are important in this field.

Four, even if judges find the best argument to make the right choice to categorize an item, it is possible that respondents to the questionnaire read other meanings in items than educated judges do.

\subsection{Uses of this method}

Our approach can be used in two ways: 1) to select existing questionnaires for use in research or HR practice, and 2) to develop a new questionnaire on perceived quality of work life.

\subsubsection{For users of questionnaires}

Common users of questionnaires on perceived QWL consist of researchers, HR departments, consulting firms and HR apps. It is important for researchers to select questionnaires that are adapted to their needs because the quality of their results and their research depends on the quality of the items of the questionnaires they have chosen. It is also important for HR departments, consulting firms and HR apps to select questionnaires that are adapted to their needs because the quality of the recommendations and the data-driven HR policies depends on the results obtained using the chosen questionnaire(s).

To select a questionnaire, users must, first, decide what information they need. The conceptual matrix presented here provides an overview of possible topics and can as such help 
a prospective user to get a clearer view of what information might be useful for them. Once they are more aware of these necessities, they can use the method to select the questionnaire that best meets these.

\subsubsection{For creators of questionnaires}

For researchers, the method presented here is just an additional technique that can be used to develop better questionnaires in conjunction with the usual psychometric techniques, preferably in the first stage of questionnaire development. For example, the item response theory (IRT) may help questionnaires developers develop items and can be used along with our approach, however, the IRT cannot bring the degree of semantic analysis present in our approach, as we argued in Sect. 3.4.

For HR departments, consulting firms and HR apps, that often do not use psychometric technique in questionnaire development, our method might be the major tool to devise questionnaires that meet their information needs.

One has to decide on which conceptual framework to orient to develop a new questionnaire in this way, such as on the matrix used in this paper. The next step is then to generate new items and, or use existing items when they fall within the framework chosen. The substantive contents of the questionnaire are then clear from the beginning; the psychometric properties come second in this process.

\subsection{Further research}

Now we have demonstrated that the method discussed here can be used to reveal contents of questionnaires that are often not well visible for potential users, a next step is to apply our method to more questionnaires on perceived quality of one's work life. The results of these analyses can be presented in an online archive from which users can select the questionnaire that fits their information needs best. This archive could also contain information about psychometric properties and benchmarking data. Such a questionnaire library does not yet exist on perceived QWL questionnaires to our knowledge.

A collection of this kind will allow academics and practitioners to check whether questionnaires that stand out as the most clear-cut conceptually also perform better on the usual correlational validity tests, the limitations of which we discussed in Sect. 1.3. In which questionnaires are substantive clarity and statistical validity found together and in which cases are they not?

Another line for further research is to consider alternative conceptual matrices. In this paper, we used Veenhoven's (2009) classification of qualities of life, which worked well when applied to questionnaires on the quality of work life, however, this conceptualization is not the only possible conceptualization, and researchers can try different conceptual lenses. Whether such alternative matrices will provide us with a better view on the contents of QWL questionnaires depends, among other things, on the clarity of the distinctions made. This clarity should reflect in the agreements of the raters who apply these matrices. 


\section{Conclusions}

There is a multitude of questionnaires on perceived quality of one's work life. These questionnaires address different qualities of work life in different combinations, and their titles typically tell us little about their contents. A comparative content analysis of a large number of questionnaires is required to choose the questionnaire that best fits an organization's information needs. This in turn requires a well-defined conceptual grid, which can be done using the adaptation to the work setting of the Veenhoven's (2009) conceptual distinction of 9 qualities of life.

Supplementary Information The online version contains supplementary material available at https:/doi. org/10.1007/s11135-021-01165-z.

Open Access This article is licensed under a Creative Commons Attribution 4.0 International License, which permits use, sharing, adaptation, distribution and reproduction in any medium or format, as long as you give appropriate credit to the original author(s) and the source, provide a link to the Creative Commons licence, and indicate if changes were made. The images or other third party material in this article are included in the article's Creative Commons licence, unless indicated otherwise in a credit line to the material. If material is not included in the article's Creative Commons licence and your intended use is not permitted by statutory regulation or exceeds the permitted use, you will need to obtain permission directly from the copyright holder. To view a copy of this licence, visit http://creativecommons.org/licenses/by/4.0/.

\section{References}

Allen, N.J., Meyer, J.P.: The measurement and antecedents of affective, continuance and normative commitment to the organization. J. Occup. Psychol. 63(1), 1-18 (1990)

Andrews, F.M., Withey, S.B.: Social Indicators of Well-Being Americans Perceptions of Life Quality. Plenum Press, New York (1976)

Aziri, B.: Job satisfaction: A literature review. Manag. Res. Pract. 3(4), 77-86 (2011)

Bacharach, S.B., Bamberger, P., Conley, S.: Work-home conflict among nurses and engineers: mediating the impact of role stress on burnout and satisfaction at work. J. Organ. Behav. 12(1), 39-53 (1991)

Bakker, A.B., Oerlemans, W.G.: Momentary work happiness as a function of enduring burnout and work engagement. J. Psychol. 150(6), 755-778 (2016)

Bagtasos, M.R.: Quality of work life: a review of literature. DLSU Bus. Econ. Rev. 20(2), 1-8 (2011)

Brayfield, A.H., Rothe, H.F.: An index of job satisfaction. J. Appl. Psychol. 35(5), 307-311 (1951)

Brook, R.H., Ware, J.E., Davies-Avery, A., Stewart, A.L., Donald, C.A., Rogers, W.H., Williams, K.N., Johnston, S.A.: Overview of adult health status measures fielded in Rand's Health Insurance Study. Med. Care 17(7), 1-131 (1979)

Brooks, B.A., Anderson, M.A.: Defining quality of nursing work life. Nurs. Econ. 23(6), 319-326 (2005)

Campbell, A., Converse, P.E., Rodgers, W.L.: The Quality of American Life: Perceptions, Evaluations, and Satisfactions. Russell Sage Foundation, London (1976)

Carlson, H.C.: A model of quality of work life as a developmental process. Educ. Train. 25(1), 27-32 (1983)

Castle, N.G.: Assessing job satisfaction of nurse aides in nursing homes: the nursing home nurse aide job satisfaction questionnaire. J. Gerontol. Nurs. 33(5), 41-47 (2007)

Csikszentmihalyi, M., LeFevre, J.: Optimal experience in work and leisure. J. Pers. Soc. Psychol. 56(5), 815$822(1989)$

Ekman, P.: Basic emotions. In: Dalgleish, T., Power, M. (eds.) Handbook of cognition and emotion, pp. 45-60. Wiley, New York (1999)

Elizur, D., Shye, S.: Quality of work life and its relation to quality of life. Appl. Psychol. 39(3), 275-291 (1990)

EORTC: Manual for quality of life questionnaire. https://qol.eortc.org/manuals/ (2000). Accessed 20 Nov 2020

Fields, D.L.: Taking the Measure of Work: A Guide to Validated Scales for Organizational Research and Diagnosis. Sage, London (2002)

Gerson, E. M.: On "quality of life". Am. Sociological Review. 793-806 (1976) 
Hinkin, T.R., Tracey, J.B.: An analysis of variance approach to content validation. Organ. Res. Methods 2(2), 175-186 (1999)

Hoppock, R.: Job satisfaction. Harper and Brothers, New York (1935)

INSEE : Enquête sur la qualité de vie (2011)

Javadi, R., Rasouli, M., Hasani, J.: Designing the questionnaire of teachers' work life quality. Iran. J. Ergon. 7(1), 10-19 (2019)

Kahneman, D.: Objective happiness. In: Kahneman, D., Diener, E., Schwarz, N. (eds.) Well-Being: The Foundations of Hedonic Psychology, pp. 3-25. Russell Sage Foundation, New York (1999)

Kainulainen, S., Saari, J., Veenhoven, R.: Life satisfaction is more a matter of feeling well than having what you want. Tests of Veenhoven's theory. Int. J. Happiness Dev. 4(3), 209-235 (2018)

Kiernan, W.E., Knutson, K.: Quality of work life. In: Schalock, R.L. (ed.) Quality of Life: Perspectives and Issues, pp. 101-114. American Association of Mental Retardation, Washington (1990)

Lester, P.E.: Development and factor analysis of the teacher job satisfaction questionnaire (TJSQ). Educ. Psychol. Measur. 47(1), 223-233 (1987)

Locke, E.A.: What is job satisfaction? Org. Behav. Hum. Perform. 4(4), 309-336 (1969)

Macdonald, S., Maclntyre, P.: The generic job satisfaction scale: scale development and its correlates. Emp. Assist. Q. 13(2), 1-16 (1997)

MacKenzie, S.B., Podsakoff, P.M., Podsakoff, N.P.: Construct measurement and validation procedures in MIS and behavioral research: integrating new and existing techniques. MIS Q. 35(2), 293-334 (2011)

Martel, J.P., Dupuis, G.: Quality of work life: theoretical and methodological problems, and presentation of a new model and measuring instrument. Soc. Indic. Res. 77(2), 333-368 (2006)

Nadler, D.A., Lawler, E.E.: Quality of work life: perspectives and directions. Organ. Dyn. 11(3), 20-30 (1983)

Phillips, D.: Quality of Life: Concept, Policy and Practice. Routledge, London (2006)

Rentsch, J.R., Steel, R.P.: Construct and concurrent validation of the Andrews and Withey job satisfaction questionnaire. Educ. Psychol. Measur. 52(2), 357-367 (1992)

Salas-Vallina, A., Lopez-Cabrales, A., Alegre, J., Fernández, R.: On the road to happiness at work (HAW): transformational leadership, organizational learning capability and happiness at work. Pers. Rev. 46(2), 314-338 (2016)

Schaufeli, W.B., Salanova, M., González-Romá, V., Bakker, A.B.: The measurement of engagement and burnout: A two sample confirmatory factor analytic approach. J. Happiness Stud. 3(1), 71-92 (2002)

Schriesheim, C., Tsui, A.N.: Development and validation of a short satisfaction instrument for use insurvey feedback interventions, paper represented at the Western Academy of Management Meeting. Phoenix AZ (1980)

Singh, S., Aggarwal, Y.: Happiness at work scale: construction and psychometric validation of a measure using mixed method approach. J. Happiness Stud. 19(5), 1439-1463 (2018)

Sirgy, M.J., Efraty, D., Siegel, P., Lee, D.J.: A new measure of quality of work life (QWL) based on need satisfaction and spillover theories. Soc. Indic. Res. 55(3), 241-302 (2001)

Smith, P.C., Kendall, L.M., Hulin, C.L.: The Measurement of Satisfaction in Work and Retirement: A Strategy for the Study of Attitudes. Rand-McNally, Chicago (1969)

Spector, P.E.: Measurement of human service staff satisfaction: development of the job satisfaction survey. Am. J. Community Psychol. 13(6), 693-713 (1985)

Spector, P.E.: Job Satisfaction: Application, Assessment, Causes and Consequences. Sage Publications, Thousand Oaks (1997)

Swamy, D.R., Nanjundeswaraswamy, T.S., Rashmi, S.: Quality of work life: scale development and validation. Int. J. Caring Sci. 8(2), 281 (2015)

Van Laar, D., Edwards, J.A., Easton, S.: The Work-Related Quality of Life scale for healthcare workers. J. Adv. Nurs. 60(3), 325-333 (2007)

Veenhoven, R.: The four qualities of life: Ordering concepts and measures of the good life. J. Happiness Stud. 1, 1-39 (2000)

Veenhoven, R.: How do we assess how happy we are? Tenets, implications and tenability of three theories. In: Dutt, A.K., Radcliff, B. (eds.) Happiness, Economics and Politics, pp. 45-69. Edward Elgar Publishing, Cheltenham (2009)

Ware Jr, J.E., Sherbourne, C.D.: The MOS 36-item short-form health survey (SF-36): I. Conceptual framework and item selection. Medical Care. 473-483 (1992)

Weiss, D.J., Dawis, R.V., England, G.W.: Manual for the Minnesota Satisfaction Questionnaire. Minnesota studies in vocational rehabilitation (1967)

Publisher's Note Springer Nature remains neutral with regard to jurisdictional claims in published maps and institutional affiliations. 